\title{
Patient and operational factors affecting wait times in a bariatric surgery program in Toronto: a retrospective cohort study
}

\author{
Adam Diamant PhD, Michelle C. Cleghorn MSc, Joseph Milner PhD, Sanjeev Sockalingam MD, \\ Allan Okrainec MD MHPE, Timothy D. Jackson MD MPH, Fayez A. Quereshy MD MBA
}

Abstract

Background: Increasing rates of obesity have led to growing demand for bariatric surgery. This has implications for wait times, particularly in publicly funded programs. This study examined the impact of patient and operational factors on wait times in a multidisciplinary bariatric surgery program.

Methods: A retrospective study was conducted involving patients who were referred to a tertiary care centre (University Health Network, Toronto Western Hospital, Toronto) for bariatric surgery between June 2008 and July 2011. Patient characteristics, dates of clinical assessments and records describing operational changes were collected. Univariable analysis and multivariable log-linear and parametric time-to-event regressions were performed to determine whether patient and operational covariates were associated with the wait time for bariatric surgery (i.e., length of preoperative evaluation).

Results: Of the 1664 patients included in the analysis, 724 underwent surgery with a mean wait time of 440 (standard deviation 198 ) days and a median wait time of 445 (interquartile range 298-533) days. Wait times ranged from 3 months to 4 years. Univariable and multivariable analyses showed that patients with active substance use $(\beta=0.3482, p=0.02)$ and individuals who entered the program in more recent operational periods $(\beta=0.2028, p<0.001)$ had longer wait times. Additionally, the median time-to-surgery increased over 3 discrete operational periods (characterized by specific program changes related to scheduling and staffing levels, and varying referral rates and defined surgical targets; $p<0.001$ ).

Interpretation: Some patients could be identified at referral as being at risk for longer wait times. We also found that previous operational decisions significantly increased the wait time in the program since its inception. Therefore, careful consideration must be devoted to process-level decision-making for multistage bariatric surgical programs, because managerial and procedural changes can affect timely access to treatment.

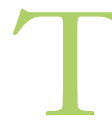
he Public Health Agency of Canada reported that nearly a quarter of all Canadians are obese (body mass index $[\mathrm{BMI}]>30 \mathrm{~kg} / \mathrm{m}^{2}$ ) at a direct cost of up to $\$ 4.6$ billion per year. ${ }^{1}$ Obesity is associated with a reduction in quality of life and decreased life expectancy, ${ }^{2,3}$ and is linked to an increased incidence of diseases such as coronary heart disease,, 4 diabetes $^{6,7}$ and certain types of cancers. ${ }^{8}$ However, bariatric surgery is recognized as a cost-effective treatment for severe obesity, ${ }^{9,10}$ resulting in sustained weight loss associated with the prevention, alleviation and resolution of many comorbid conditions. ${ }^{11,12}$

Given the effectiveness of bariatric surgery for severe obesity ${ }^{13,14}$ and rising demand for surgical intervention, in 2009, the Ontario Ministry of Health and Long-Term Care invested $\$ 75$ million to increase the number of surgeries performed in the province from 244 to 1470 per year by $2012 . .^{15}$ Four Bariatric Centres of Excellence were established that deliver care based on a multidisciplinary, multistage presurgical assessment process to appropriately identify suitable candidates for surgery. ${ }^{16}$ However, this model of care has led to prolonged preoperative evaluation, resulting in wait times that far exceed the provincially mandated target of 365 days from referral to surgery. The consequences of delayed surgery may include increased patient attrition, ${ }^{17}$ decreased patient satisfaction and delayed improvement in obesity-related comorbidities. Although a comprehensive evaluation is necessary and an extended preoperative course may be important to facilitate patient education and commitment, ${ }^{18}$ patients may also feel

Competing interests: None declared.

This article has been peer reviewed.

Correspondence to: Fayez A. Quereshy, fayez.quereshy@uhn.ca CMAJ Open 2015. DOI:10.9778/cmajo.20150020 
discomfort with a longer wait time for surgery. In contrast to previous survey-based research on wait times for bariatric surgery, ${ }^{19-21}$ this study quantified how patient characteristics and operational factors contribute to excessive wait times in a large bariatric surgery program.

\section{Methods}

\section{Study design, setting and participants}

We conducted a retrospective review involving patients referred for bariatric surgery at a tertiary care centre (University Health Network, Toronto Western Hospital, Toronto), between June 1, 2008, and July 31, 2011. Only patients who underwent bariatric surgery or withdrew from the program at the time of data collection were included. We identified a total of 1682 eligible participants met the inclusion criteria. As a multidisciplinary, multistage program, the preoperative evaluation includes medical, social work, dietary, psychological or psychiatric assessments, and a surgical consultation before patients are deemed eligible for surgery (Figure 1). ${ }^{16}$ If substantial clinical or psychosocial issues are identified, an interdisciplinary team reviews each patient's case to determine if intervention is appropriate or if they should be refused surgery. Patients must be cleared at each stage before moving on in the program. All physician referrals are administered through the Ontario Bariatric Network and distributed among regionalized surgical programs in the province. Selection criteria for referral are standardized across all Ontario bariatric surgical centres. ${ }^{22}$ All referred patients had a BMI greater than $40 \mathrm{~kg} / \mathrm{m}^{2}$ or a BMI greater than $35 \mathrm{~kg} / \mathrm{m}^{2}$ with at least 1 obesity-related comorbidity.

\section{Operational periods}

Several procedural changes took place during the study period (Table 1). We distinguished between 3 operational phases, because many of these interventions occurred at once. Each operational period was characterized by a unique set of managerial and administrative changes, related to fluctuations in staffing levels, referral rate, surgical target, and alterations in scheduling practices and new internal policy. The first period corresponds to early program performance (baseline levels), and the third period represents the most recent operational landscape. Staffing levels and the physical space reserved for assessments increased in each period since the program's inception.

\section{Data collection and outcome measures}

Patient characteristics (height, weight and BMI) including demographic information (age, sex and postal code), possible exclusion criteria for surgery (substance use including smoking, alcohol and drug use) and the dates of each assessment including surgery were collected from the referral document and electronic patient records. We used a broad definition for substance use because any substance use is a contraindication for surgery and must be stopped before a patient can have surgery. Data were linked to operational records describing procedural changes. The referral dates for 5 patients and the physical charts for 13 patients were missing, and, therefore, they were excluded from the analysis.

The primary outcome was the overall wait time for bariatric surgery. This represents patients who completed all preoperative assessments. We also examined the total wait time for patients who attended an orientation session, therefore focusing on patients who showed a willingness to participate in the program. Patients who attended orientation but did not undergo surgery were censored as of their last appointment date.

\section{Statistical analysis}

We used the R programming environment for data analysis. A random forest technique was used to impute missing data. ${ }^{23}$ Group comparisions were made using univariable, nonparametric statistical testing. As recommended in the STROBE statement, ${ }^{24} \mathrm{BMI}$, age and distance were modelled as both continuous and categorical variables. We used multivariable regression analysis to determine the association between patient and operational covariates and total wait time for all patients who underwent bariatric surgery (log-linear) and all patients who attended orientation but who did not necessarily undergo surgery (parametric time-to-event). Departures from linearity were assessed by plotting a locally weighted scatter plot curve through the Martingale residuals. We tested the appropriateness of the regression models by performing a global validation of model assumptions, a variance inflation test for multicollinearity, a Breusch-Pagan test for heteroskedasticity and a

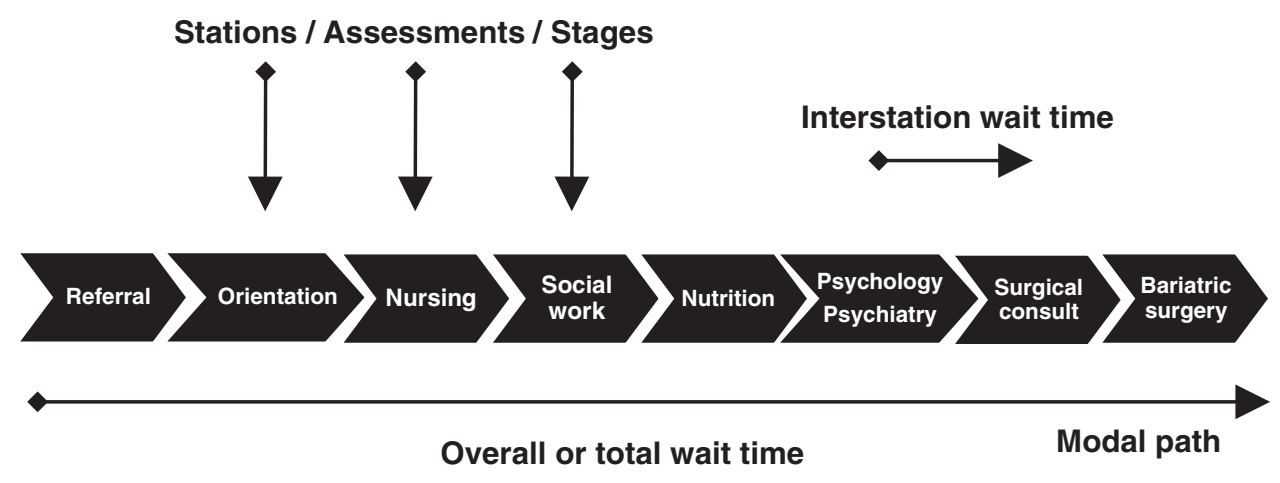

Figure 1: Patient flow through the bariatric surgery program. 
Q-Q plot of the residuals for normality. A 95\% confidence interval (CI) was used to assess statistical significance.

The study protocol was approved by the University Health Network Research Ethics Board.

\section{Results}

\section{Univariable analysis}

Of the 1664 patients included in the analysis, 724 underwent surgery with a mean wait time of 440 SD 198) days and a median wait time of 445 (interquartile range [IQR] 298-533) days. Wait times ranged from 3 months to 4 years. The majority of referred patients $(74.4 \%)$ and those who had surgery $(80.8 \%)$ were female. Patients who did not reach surgery either dropped out of the program (self-removal) or were refused surgery because of substantial clinical or psychosocial issues (removal from the program on the advice of the interdisciplinary team). The average age at referral was 48 (SD 11.3) years, and few patients $(n=42)$ with active substance use were referred to the program. The median patient distance to the hospital was $48.2 \mathrm{~km}$ (range 1-550 km). The values for the referral BMI of 83 patients were missing; therefore, we employed a nonparametric multiple imputation procedure to provide estimates of BMI for those patients. The out-of-bag error estimate was 3.6\%.

Differences in wait time for surgery by patient characteristic and operational period are shown in Table 2. We found no difference in the length of the preoperative assessment among patients by age $\left(\chi^{2}=6.538, d f=4, p=0.2\right)$, BMI $\left(\chi^{2}=3.186\right.$, $d f=3, p=0.4)$ and by distance from the hospital $\left(\chi^{2}=6.256\right.$, $d f=6, p=0.4)$. However, subsequent analysis using the Wilcoxon rank sum test (also known as the Mann-Whitney test) showed that the median distance to hospital for patients who attended multiple assessments in 1 day was $30 \mathrm{~km}$ farther than the distance for patients who did not have this type of assessment schedule $(W=36780.6, p<0.001)$. Males $(W=36433.5$, $p=0.042)$, individuals with active substance use $(W=1596.5$, $p=0.009)$ and patients who attended an orientation session in

\begin{tabular}{|c|c|c|c|}
\hline Operational change & Period 1 & Period 2 & Period 3 \\
\hline Staffing levels & Baseline & $\Uparrow$ & $\Uparrow$ \\
\hline Surgical target† & 180 & 300 & 270 \\
\hline Physician referral rate & Baseline & $\Uparrow$ & $\Leftrightarrow \S$ \\
\hline Internal procedures & - & $\begin{array}{l}\text { Follow-up } \\
\text { scheduling? }\end{array}$ & $\begin{array}{l}\text { No-show } \\
\text { policy** }^{*}\end{array}$ \\
\hline \multicolumn{4}{|c|}{$\begin{array}{l}\text { *Adapted from Table } 3 \text { in Diamant et al. (2014). }{ }^{17} \\
\text { †Represents the maximum allowable number of surgeries that can be performed } \\
\text { annually as defined by the Ontario provincial government. } \\
\text { †Represents the average number of weekly referrals by primary care physicians. } \\
\text { \$No change. } \\
\text { १Scheduling began to include follow-up appointments for patients who had } \\
\text { undergone surgery. } \\
{ }^{* *} \text { Formal removal process initiated for no-show patients (i.e., patients who failed } \\
\text { to attend } 3 \text { scheduled assessments). }\end{array}$} \\
\hline
\end{tabular}

Period 2 ( $W=44809, p<0.001)$, experienced a longer overall wait time. Patients who had surgery in Period 3 spent more time in the program than in any other period $\left(\chi^{2}=160.8, d f=2\right.$, $p<0.001)$. Differences between the surgery and no-surgery cohorts are summarized in Table 3. A more detailed analysis of factors affecting attrition was presented in a previous study. ${ }^{17}$

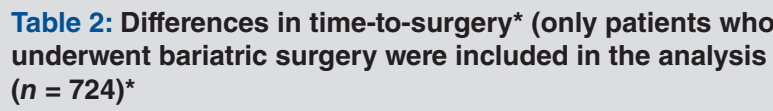
underwent bariatric surgery were included in the analysis $(n=724)^{\star}$

\begin{tabular}{|lcr|}
\hline Characteristic & $\begin{array}{c}\text { Median (IQR) } \\
\text { time-to-surgery, d }\end{array}$ & $p$ value \\
\hline Sex & & $0.04 \dagger$ \\
\hline Male & $446(327-580)$ & \\
\hline Female & $409(293-525)$ & \\
\hline
\end{tabular}

Substance use

$0.009 \dagger$

$\begin{array}{ll}\text { Yes } & 557(522-630) \\ \text { No } & 413(294-532)\end{array}$

BMI, $\mathrm{kg} / \mathrm{m}^{2}$

35-39 $418(275-605)$

0.4

$40-49 \quad 412(297-520)$

50-59 $414(293-540)$

$\geq 60 \quad 444(334-532)$

Age, yr

19-29 414 (337-599)

30-39 $404(307-527)$

$40-49 \quad 410(276-527)$

50-59 $415(293-515)$

$\geq 60 \quad 473(351-567)$

Distance, $\mathrm{km} \quad 0.4$

0-25 $405(272-520)$

25-50 $417(271-533)$

$50-100$

$100-200$

200-300 $398(308-483)$

$300-400 \quad 450(370-525)$

$400-500 \quad 418(341-523)$

$>500 \quad 474(322-627)$

Operational period (orientation) $<0.001 \dagger$

\begin{tabular}{|c|c|}
\hline 1 & $369(226-519)$ \\
\hline 2 & $432(335-539)$ \\
\hline Operational period (surgery) & \\
\hline 1 & $373(164-514)$ \\
\hline 2 & $381(273-480)$ \\
\hline 3 & 608 (482-784) \\
\hline
\end{tabular}

Note: $\mathrm{BMI}=$ body mass index, $\mathrm{IQR}=$ interquartile range

*The Mann-Whitney test (Kruskal-Wallis test) was used to determine whether 2 ( 3 or more) populations spent a similar amount of time in the program. $t p<0.05$ was considered statistically significant. 


\section{Multivariable analysis}

The results of a log-linear regression of wait time on covariates known at referral are presented in Table 4. Only patients who underwent bariatric surgery were included in this analysis. Patients with active substance use $(\beta=0.3482, p=0.02)$ and those who attended orientation in Period $2(\beta=0.2028$, $p<0.001)$ spent more time in the program. A multivariable time-to-event regression for patients who attended an orientation session is shown in Table 5. Again, patients with active substance use $(\beta=1.489, p=0.024)$ and those who attended orientation in Period $2(\beta=1.279, p<0.001)$ spent more time in the program.

We conducted additional multivariable analyses using power-transformed regression to explore how covariates affected the wait time between 2 contiguous preoperative assessments (interstation wait time). Several regression models were estimated and they confirmed the results presented above (not shown). Specifically, active substance use and operational period were statistically significant in all models. Wait times increased with operational period and showed a worsening trend. Additionally, the time between referral and orientation was slightly reduced for males and older patients, whereas interstation wait time increased with the logarithm of distance from the hospital in the early stages of the program only.

The mean wait time between specific assessment stations (and by operational period) is presented in Table 6. The highlighted cells represent the expected sequence of appointments as determined by program directors. Although this is the modal pathway, many patients deviated from this sequence of care.

\section{Interpretation}

Our results showed that specific patient profiles and operational period are associated with longer wait times. We found that the time patients spent in the program did not depend on $\mathrm{BMI}$ and was generally insensitive to age, sex and distance from the bariatric centre. However, active substance use was associated with longer wait times, and patients who attended orientation in Period 2 or who had surgery in Period 3 had longer wait times. We also showed that process-level changes are associated with worsening wait times (i.e., since the program was established, the wait time has steadily increased despite several operational interventions). Furthermore, patients spent 75 days longer, on average, in the program than the government-mandated target for bariatric surgery. Whereas $46 \%$ of that time was spent between referral and orientation, $71 \%$ of all patient transitions between assessments took longer than 30 days. This is a problematic trend that could impact timely patient access to treatment.

Substance use was associated with longer preoperative evaluation and was shown to independently predict overall wait time. This may be partially explained by the 3 -month abstinence requirement before patients can attend further preoperative assessments or the 6-month abstinence requirement before patients can proceed to surgery. Despite active substance use being an exclusion criterion for referral, more stringent practices may need to be adopted that would allow programs to refuse admittance to patients with uncontrolled substance dependencies. Our results showed that active sub-

\begin{tabular}{|c|c|c|c|}
\hline Characteristic & Surgery & No surgery & $p$ value \\
\hline Sex & & & $<0.001 \S$ \\
\hline Male & 139 & 287 & \\
\hline Female & 585 & 653 & \\
\hline Substance use & & & $<0.001 \S$ \\
\hline Yes & 9 & 33 & \\
\hline No & 715 & 907 & \\
\hline $\mathrm{BMI}, \mathrm{kg} / \mathrm{m}^{2} ;$ mean $\pm \mathrm{SD}$ & $48.87 \pm 8.19$ & $47.67 \pm 7.92$ & $0.003 \S$ \\
\hline Age, yr; mean \pm SD & $46.78 \pm 10.54$ & $48.42 \pm 11.86$ & $0.003 \S$ \\
\hline Distance from the hospital, $\mathrm{km}$; mean $\pm \mathrm{SD}$ & $119.73 \pm 179.49$ & $113.64 \pm 177.57$ & 0.5 \\
\hline Operational period (referral)† & & & $0.047 \S$ \\
\hline 1 & 478 & 575 & \\
\hline 2 & 246 & 347 & \\
\hline Operational period (orientation) $\ddagger$ & & & $<0.001 \S$ \\
\hline 1 & 233 & 155 & \\
\hline 2 & 490 & 507 & \\
\hline \multicolumn{4}{|c|}{$\begin{array}{l}\text { Note: } \mathrm{BMI}=\text { body mass index. } \\
{ }^{*} \text { The Pearson } \chi^{2} \text { test and Student } t \text { test were used as appropriate. } \\
\text { †Binary variable indicating if a patient was referred in Period } 1 \text { or Period } 2 \text {. } \\
\text { fBinary variable indicating if a patient attended orientation in Period } 1 \text { or Period } 2 \text {. } \\
\S p<0.05 \text { was considered statistically significant. }\end{array}$} \\
\hline
\end{tabular}


stance users are still referred for surgery. Enforcing the policy to restrict program entry until patients can demonstrate prolonged abstinence or until they are referred again would help to relieve system congestion and reduce wait times for patients identified as ideal surgical candidates. Moreover, patients presenting with substance use should be identified at the time of referral, because they are less likely to undergo bariatric surgery. ${ }^{17}$ This would facilitate earlier behavioural modification (e.g., smoking cessation) and delay immersion into an already resource-constrained system. However, restrictions at the provincial level may limit the autonomy that programs and individual providers have in deciding which patients should not be considered for surgery based on efficacy and safety concerns. Conversely, living farther away from the bariatric centre did not lead to increased wait times for patients. Although distance may affect the wait time between appointments, patients who lived farther away from the hospital tended to cluster their appointments (i.e., schedule multiple consecutive assessments on a single day) and made fewer trips. This finding is supported by a previous study that showed that distance did not appear to be a barrier to care in this setting. ${ }^{17}$

Operational period, as characterized by specific managerial and procedural changes, influenced wait times. Patients who had surgery in Period 3 spent more time in the program than in any other period. This suggests that process-level decisionmaking that guided operational practices did not mitigate increases in demand. During Period 3, the maximum available weekly appointments were scheduled, and patients who had already undergone bariatric surgery were being scheduled for postsurgical follow-ups at several assessment stations. As the number of surgeries increased, so did the number of patients needing follow-up appointments, and, therefore, a smaller pool of appointments were available to the increasing num-

\begin{tabular}{|c|c|c|c|}
\hline Covariates* $^{*}$ & Estimate \pm SE, d & $t$ & $p$ value \\
\hline (Intercept) & $334.7 \pm 30.3$ & 64.32 & 0.0000 \\
\hline Substance use & $139.4 \pm 73.8$ & 2.27 & $0.02 \ddagger$ \\
\hline Age & $-0.034 \pm 0.54$ & -0.08 & 0.9 \\
\hline \multicolumn{4}{|l|}{$\mathrm{BMI}, \mathrm{kg} / \mathrm{m}^{2}$} \\
\hline $40-49$ & $-11.93 \pm 19.40$ & -0.60 & 0.5 \\
\hline $50-59$ & $-2.10 \pm 21.7$ & -0.10 & 0.9 \\
\hline $60+$ & $-1.64 \pm 26.48$ & -0.06 & 0.9 \\
\hline Male & $22.23 \pm 15.69$ & 1.47 & 0.1 \\
\hline Log, distance & $3.668 \pm 4.142$ & 0.89 & 0.4 \\
\hline $\begin{array}{l}\text { Operational } \\
\text { period } 2 \dagger\end{array}$ & $75.25 \pm 16.73$ & 5.44 & $<0.001 \ddagger$ \\
\hline \multicolumn{4}{|c|}{$\begin{array}{l}\text { Note: } \mathrm{BMI}=\text { body mass index. } \\
\text { *Baseline covariate values: female, no substance use, } 19 \text { years of age, BMI } \\
\text { between } 35 \text { and } 39 \mathrm{~kg} / \mathrm{m}^{2} \text {, lived within a few kilometres of the bariatric centre, } \\
\text { and referred or attended orientation in Period } 1 . \\
+ \text { Binary variable indicating if a patient attended orientation in Period } 2 \text {. } \\
\ddagger p<0.05 \text { was considered statistically significant. }\end{array}$} \\
\hline
\end{tabular}

bers of presurgical patients. This operational roadblock may explain why the surgical target was subsequently lowered in Period 3 from that in Period 2 despite an increase in the referral rate. Finally, changes in internal operating procedures, specifically the initiation of a formal removal process for no-show patients, also may have contributed to reduced operational performance. Although wait times could be improved through initiatives to expand capacity, obtaining additional resources is not possible within the current funding envelope. Novel scheduling techniques need to be introduced to achieve optimization. For instance, preferential scheduling practices or combined assessments ${ }^{25}$ could be used to prioritize patients at low-risk for long wait times and noncompletion. These patients would be fast-tracked through the program while more resources are directed toward patients requiring intensive evaluation. Other interventions can also be implemented to improve performance, such as group counselling ${ }^{26,27}$ and enhanced triaging of patients. For instance, if relevant medical and psychosocial information is collected at referral, ${ }^{25}$ patients can be directed to assessments that best address any potential clinical issues early in their sequence of care.

This study represents the experience of a Canadian institution and a bariatric program operating within a public funding model. It was limited to retrospective data and did not take into account information that was learned by providers at presurgical assessments. It has implications for other types of multidisciplinary programs across different clinical specialties that involve longitudinal assessment of patients in a complex

\begin{tabular}{|c|c|c|}
\hline Distribution parameters & \multicolumn{2}{|c|}{ Estimate \pm SE, $d$} \\
\hline Mean & \multicolumn{2}{|c|}{$431.80 \pm 28.79$} \\
\hline SD & \multicolumn{2}{|c|}{$1.6117 \pm 0.195$} \\
\hline Covariates $†$ & OR $(95 \% \mathrm{Cl})$ & $p$ value \\
\hline Substance use & $1.49(1.144-1.937)$ & $0.02 \S$ \\
\hline Age & $1.00(0.998-1.004)$ & 0.8 \\
\hline \multicolumn{3}{|l|}{$\mathrm{BMI}, \mathrm{kg} / \mathrm{m}^{2}$} \\
\hline $40-49$ & $0.93(0.834-1.030)$ & 0.05 \\
\hline $50-59$ & $0.95(0.849-1.070)$ & 0.3 \\
\hline $60+$ & $0.93(0.808-1.073)$ & 0.06 \\
\hline Male & $1.09(1.005-1.175)$ & 0.08 \\
\hline Log, distance & $0.98(0.962-1.050)$ & 0.07 \\
\hline Operational Period $2 \ddagger$ & $1.28(1.194-1.370)$ & $<0.001 \S$ \\
\hline
\end{tabular}

Note: $\mathrm{BMI}=$ body mass index $\mathrm{Cl}=$ confidence interval, $\mathrm{OR}=$ odds ratio. *Parametric time-to-event regression with log-normal hazards. Dependent variable was time-to-surgery. Patients who did not undergo bariatric surgery were censored at their last assessment date. Patients who did not attend orientation were excluded from the analysis.

†Baseline covariate values: female, no substance use, 19 years of age, BMI between 35 and $39 \mathrm{~kg} / \mathrm{m}^{2}$, lived within a few kilometres of the bariatric centre, and referred or attended orientation in Period 1.

$\neq$ Binary variable indicating if a patient attended orientation in Period 2 $\S p<0.05$ was considered statistically significant. 
Table 6: Mean wait times for observed station transitions and by operational period (Periods 1-Period 3)*

\begin{tabular}{|c|c|c|c|c|c|c|c|}
\hline \multirow[b]{3}{*}{ From } & \multicolumn{7}{|c|}{ Mean wait time $\pm S D, d$} \\
\hline & \multicolumn{7}{|c|}{ To } \\
\hline & Orientation & Nursing & Social work & Nutrition & $\begin{array}{l}\text { Psychology, } \\
\text { psychiatry }\end{array}$ & $\begin{array}{l}\text { Surgical } \\
\text { consult }\end{array}$ & Surgery \\
\hline Referral & $\begin{array}{c}203 \pm 150 \\
(162,219,-)\end{array}$ & - & - & - & - & - & - \\
\hline Orientation & - & $\begin{array}{c}49 \pm 55 \\
(29,54,-)\end{array}$ & $\begin{array}{c}43 \pm 103 \\
(19,63,-)\end{array}$ & $\begin{array}{c}59 \pm 132 \\
(34,174,-)\end{array}$ & - & - & - \\
\hline Nursing & - & - & $\begin{array}{c}19 \pm 41 \\
(3,20,86)\end{array}$ & $\begin{array}{c}19 \pm 38 \\
(5,34,21)\end{array}$ & $\begin{array}{c}24 \pm 30 \\
(17,31,-)\end{array}$ & $\begin{array}{c}50 \pm 50 \\
(34,54,64)\end{array}$ & - \\
\hline Social work & - & $\begin{array}{c}23 \pm 28 \\
(12,26,-)\end{array}$ & - & $\begin{array}{c}43 \pm 53 \\
(12,45,131)\end{array}$ & $\begin{array}{c}32 \pm 37 \\
(16,39,51)\end{array}$ & $\begin{array}{c}37 \pm 37 \\
(13,45,-)\end{array}$ & - \\
\hline Nutrition & - & $\begin{array}{c}42 \pm 62 \\
(30,54,-)\end{array}$ & $\begin{array}{c}37 \pm 36 \\
(36,39,-)\end{array}$ & - & $\begin{array}{c}22 \pm 38 \\
(18,22,42)\end{array}$ & $\begin{array}{c}65 \pm 63 \\
(17,75,94)\end{array}$ & - \\
\hline Psychology, psychiatry & - & $\begin{array}{c}18 \pm 16 \\
(11,41,-)\end{array}$ & $\begin{array}{c}47 \pm 55 \\
(51,34,125)\end{array}$ & $\begin{array}{c}45 \pm 64 \\
(39,44,82)\end{array}$ & - & $\begin{array}{c}61 \pm 83 \\
(15,49,168)\end{array}$ & $\begin{array}{c}68 \pm 55 \\
(14,76,119)\end{array}$ \\
\hline Surgical consult & - & - & $\begin{array}{c}52 \pm 64 \\
(15,61,84)\end{array}$ & $\begin{array}{c}61 \pm 95 \\
(5,46,334)\end{array}$ & $\begin{array}{c}40 \pm 34 \\
(6,58,-)\end{array}$ & - & $\begin{array}{c}66 \pm 60 \\
(36,62,92)\end{array}$ \\
\hline
\end{tabular}

system (e.g., transplant and oncology). Direct application of these findings may be limited, because bariatric surgery is an elective procedure that, if not performed urgently, does not have immediate patient consequences.

Our analysis has revealed 3 areas for improvement. First, certain types of patients should be identified early in the process, and program administrators may want to develop customized care plans that address their specific needs. Second, the current exclusion criteria for surgery may be too lenient, especially the criteria that relate to substance use. Third, previous operational interventions have not decreased wait times. We are currently investigating how to schedule patients for assessments to improve health care provider utilization, and what the optimal proportion of new to follow-up appointment slots should be. Furthermore, better triaging enables early treatment and relevant diagnostic tests (e.g., blood work, sleep study) to be completed even while patients undergo further assessments. This would decrease the waiting time when patients are closer to surgery and could also reduce late-stage patient attrition. Future research will identify triage techniques that improve wait times within this unique clinical setting. Additional inquiry into the effectiveness of a longitudinal care model and utility of a 1-year target wait time for measuring efficiency is also needed.

\section{References}

1. Obesity in Canada. A Joint Report from the Public Health Agency of Canada and the Canadian Institute for Health Information. Ottawa: Public Health Agency of Canada; Canadian Institute for Health Information; 2011. Available: www.phac-aspc. gc.ca/hp-ps/hl-mvs/oic-oac/assets/pdf/oic-oac-eng.pdf (accessed 2015 July 23).

2. Fontaine KR, Barofsky I. Obesity and health-related quality of life. Obes Rev 2001;2:173-82

3. Peeters A, Barendregt JJ, Willekens F, et al. Obesity in adulthood and its consequences for life expectancy: a life-table analysis. Ann Intern Med 2003; 138:24-32.

4. Manson JE, Colditz GA, Stampfer MJ, et al. A prospective study of obesity and risk of coronary heart disease in women. N Engl 7 Med 1990;322:882-9.

5. Rimm EB, Stampfer MJ, Giovannucci E, et al. Body size and fat distribution as predictors of coronary heart disease among middle-aged and older US men. Am 7 Epidemiol 1995;141:1117-27.

6. Colditz GA, Willett WC, Rotnitzky A, et al. Weight gain as a risk factor for clinical diabetes mellitus in women. Ann Intern Med 1995;122:481-6.

7. Manson JE, Nathan DM, Krolewski AS, et al. A prospective study of exercise and incidence of diabetes among US male physicians. FAMA 1992;268:63-7.

8. Calle EE, Rodriguez C, Walker-Thurmond K, et al. Overweight, obesity, and mortality from cancer in a prospectively studied cohort of US adults. $N$ Engl 7 Med 2003;348:1625-38.

9. Gallagher SF, Banasiak M, Gonzalvo JP, et al. The impact of bariatric surgery on the Veterans Administration healthcare system: a cost analysis. Obes Surg 2003; $13: 245-8$.

10. Deitel M. Bariatric surgery is a cost-saving for the healthcare system. Obes Surg 2005;15:301-3.

11. Dhabuwala A, Cannan RJ, Stubbs RS. Improvement in co-morbidities following weight loss from gastric bypass surgery. Obes Surg 2000;10:428-35.

12. Maggard MA, Shugarman LR, Suttorp M, et al. Meta-analysis: surgical treatment of obesity. Ann Intern Med 2005;142:547-59.

13. Buchwald H, Estok R, Fahrbach K, et al. Trends in mortality in bariatric surgery: a systematic review and meta-analysis. Surgery 2007;142:621-32.

14. Sjöström L, Lindroos AK, Peltonen $M$, et al. Lifestyle, diabetes, and cardiovascular risk factors 10 years after bariatric surgery. $N$ Engl 7 Med 2004;351: 2683-93.

15. Ontario Ministry of Health and Long-Term Care. Ontario improves access to bariatric surgery. McGuinty government moving forward on diabetes strategy [news release]. 2009 Feb. 23. Available: http://news.ontario.ca/mohltc/en/2009 /02/ontario-improves-access-to-bariatric-surgery.html (accessed 2015 July 23).

16. Mechanick JI, Youdim A, Jones DB, et al. Clinical practice guidelines for the perioperative nutritional, metabolic, and nonsurgical support of the bariatric surgery patient - 2013 update: cosponsored by American Association of Clinical Endocrinologists, The Obesity Society, and American Society for Metabolic \& Bariatric Surgery. Obesity (Silver Spring) 2013;21(Suppl 1):S1-27.

17. Diamant A, Milner J, Cleghorn M, et al. Analysis of patient attrition in a publicly funded bariatric surgery program. 7 Am Coll Surg 2014;219:1047-55.

18. van Hout GC, Verschure SK, van Heck GL. Psychosocial predictors of success following bariatric surgery. Obes Surg 2005;15:552-60.

19. Christou NV, Efthimiou E. Bariatric surgery waiting times in Canada. Can $\mathcal{f}$ Surg 2009;52:229-34.

20. Padwal RS, Majumdar SR, Klarenbach S, et al. Health status, quality of life, 
and satisfaction of patients awaiting multidisciplinary bariatric care. $B M C$ Health Serv Res 2012;12:139.

21. Gregory DM, Temple Newhook J, Twells LK. Patients' perceptions of waiting for bariatric surgery: a qualitative study. Int 7 Equity Health 2013;12:86.

22. Surgical program. Toronto: Ontario Bariatric Network; 2015. Available: www. ontariobariatricnetwork.ca/our-programs/surgical-program\#tabs-5 (accessed 2015 Apr. 15).

23. Stekhoven DJ, Buhlmann P. MissForest - non-parametric missing value imputation for mixed-type data. Bioinformatics 2012;28:112-8.

24. Vandenbroucke JP, von Elm E, Altman DG, et al. Strengthening the Reporting of Observational Studies in Epidemiology (STROBE): explanation and elaboration. Epidemiology 2007;18:805-35.

25. Merrell J, Ashton K, Windover A, et al. Psychological risk may influence dropout prior to bariatric surgery. Surg Obes Relat Dis 2012;8:463-9.

26. Sikon A, Bronson DL. Shared medical appointments: challenges and opportunities. Ann Intern Med 2010;152:745-6.

27. Burke RE, O'Grady ET. Group visits hold great potential for improving diabetes care and outcomes, but best practices must be developed. Health Aff (Millwood) 2012;31:103-9.

Affiliations: Rotman School of Management (Diamant, Milner), University of Toronto, Toronto, Ont.; Division of General Surgery (Cleghorn,
Okrainec, Jackson, Quereshy) and Department of Psychiatry (Sockalingam), University Health Network, University of Toronto, Toronto, Ont.

Contributors: Adam Diamant, Joseph Milner, Sanjeev Sockalingam, Allan Okrainec, Timothy D. Jackson and Fayez Quereshy contributed substantially to the conception and design. Adam Diamant and Fayez Quereshy acquired the data, which was analyzed and interpreted by Adam Diamant, Joseph Milner, Michelle Cleghorn and Fayez Quereshy. Adam Diamant and Michelle Cleghorn drafted the manuscript. Joseph Milner, Sanjeev Sockalingam, Allan Okrainec, Timothy Jackson and Fayez Quereshy critically revised the manuscript for important intellectual content. All of the authors gave final approval of the version to be published and agreed to act as guarantors of the work.

Funding: This study was funded by the Ontario Academic Health Science Centres Innovation Fund. The funder had no involvement in the study or its publication.

Supplemental information: For reviewer comments and the original submission of this manuscript, please see www.cmajopen.ca/content/3/3/ E331/suppl/DC1 